Revista de

Contabilidade e Organizações

www.rco.usp.br
DOI: http://dx.doi.org/10.11606/issn.1982-6486.rco.2019.158537
Journal of

Accounting and

Organizations

\title{
Influência dos traços de personalidade no ceticismo profissional de auditores independentes
}

\author{
Influence of personality traits in the professional skepticism of auditors \\ Paulo Roberto da Cunha ${ }^{\mathrm{a}}$, Crisiane Teixeira da Silva ${ }^{\mathrm{a}}$, Danrlei Anderson Peyerl ${ }^{\mathrm{a}}$, Juçara Haveroth ${ }^{\mathrm{a}}$
}

${ }^{a}$ Universidade Regional de Blumenau

\section{Palavras-chave}

Ceticismo profissional.

Traços de personalidade.

Auditores independentes.

Fraudes.

Qualidade de auditoria.
Keywords

Professional skepticism.

Personality traits.

Auditors.

Frauds.

Audit quality.
Informações do Artigo

Recebido: 30 de maio de 2019

Aceito: 21 de novembro de 2019

Publicado: 29 de novembro de 2019

\section{Resumo}

Esta pesquisa teve por objetivo verificar a influência dos traços de personalidade no ceticismo profissional de auditores no Brasil. A amostra corresponde a 321 auditores cadastrados no Conselho Federal de Contabilidade (CFC), com perfis ativos no LinkedIn ${ }^{\circledR}$. O ceticismo profissional contempla as dimensões: mente questionadora, suspensão do julgamento, busca do conhecimento, conhecimento interpessoal, autoestima e autonomia (Hurtt, 2010) e o traço de personalidade é engloba as dimensões abertura à experiência, consciência, extroversão, amabilidade e neuroticismo (Gosling et al., 2003). Os resultados demonstram que os traços de personalidade explicam $22 \%$ do ceticismo profissional dos auditores, e que a abertura à experiência e a consciência possuem uma relação positiva com o ceticismo profissional, enquanto a amabilidade demonstrou uma relação negativa. O estudo sinaliza aos órgãos reguladores, auditores e firmas de auditoria que os traços de personalidade influenciam na formação do traço cético dos auditores. Assim, observar essas características pode contribuir para entender este comportamento durante o processo de auditoria.

\begin{abstract}
This research aimed to verify the influence of personality traits on auditors' professional skepticism in Brazil. One sample is 321 auditors registered with the

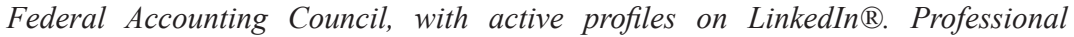
skepticism has the following dimensions: questioning mind, suspension of judgment, search for knowledge, interpersonal understanding, self-esteem and autonomy (Hurtt, 2010), and the personality trait is composed by openness to experience, conscientiousness, extraversion, agreeableness and neuroticism (Gosling et al., 2003). The results demonstrated by the personality traits explain $22 \%$ of the auditors, professional skepticism, and that openness to experience and conscientiousness has a positive relationship with the professional skepticism, while agreeableness shows a negative relationship. The results signal to regulators, auditors and audit firms that the personality traits influence the formation of auditors spetical traits. Because, observing these characteristics can help to understand this behavior during the audit process.
\end{abstract}

\section{Implicações práticas}

Uma forma eficaz de se ter auditores céticos perpassa pela contratação daqueles que possuem maiores traços céticos e características de personalidade que melhor se adequem ao ambiente do trabalho de auditoria. Nessas condições ressalta-se a necessidade de mapear e conhecer as variáveis pessoais, analisadas neste estudo, que influenciam a mentalidade cética.

Copyright (C) 2019 FEA-RP/USP. Todos os direitos reservados

\footnotetext{
Autor Correspondente: Tel. (47) 3321-0565

E-mail: pauloccsa@furb.br (P. R. da Cunha); crisianes@furb.br (C. T. da Silva); dpeyerl@furb.br(D. A. Peyerl); jucara_haveroth@hotmail.com (J. Haveroth)

Universidade Regional de Blumenau. Rua Antônio da Veiga, 140 - Victor Konder, Blumenau/SC - 89012900 , Brasil.
} 


\section{INTRODUÇÃO}

As diversas fraudes contábeis ocorridas no início dos anos 2000, envolvendo empresas como Enron e Worldcom, além de firmas de auditoria como a Arthur Andersen, lançaram luz a questionamentos quanto a qualidade do trabalho dos auditores. A criação da Lei Sarbanes-Oxley (SOX) e do órgão regulador Public Company Accounting Oversight Board (PCAOB), no cenário norte-americano, foram ações tomadas a fim de estabelecer a criação de mecanismos de controle e de segurança, com o propósito de mitigar riscos nos negócios e procurar contribuir para o reestabelecimento da confiança no mercado financeiro.

Neste período, Beasley, Carcello e Hermanson (2001) apresentaram as dez maiores deficiências decorrentes de casos de fraudes apurados pela Securities and Exchange Commission (SEC) para os anos de 1987 a 1997. De acordo com os autores, as três maiores deficiências identificadas referem-se a coleta insuficiente de evidências de auditoria (80\%), a falta do devido cuidado profissional (71\%) e, o inapropriado nível de ceticismo profissional (60\%).

A reincidência de fraudes financeiras e de grandes escândalos torna frequente a preocupação e a discussão quanto suas consequências, destacando-se entre elas as perdas monetárias e os danos à reputação dos auditores. Em 2018 a PricewaterhouseCoopers $(\mathrm{PwC})$ constatou que fraudes e crimes econômicos, nos 24 meses anteriores à pesquisa, custaram a 30\% das empresas no mundo (no Brasil, 37\%), entre US\$ 100 mil a US\$ 5 milhões, e a 9\% dessas empresas (no Brasil, 14\%) acima de US\$ 5 milhões.

As falhas da auditoria na identificação de fraudes e crimes financeiros não prejudica apenas os auditores. Tais falhas comprometem todo o sistema financeiro e, por isso, impactam diretamente a sociedade. Tal fato, impulsiona a discussão sobre os diversos temas que envolvam a melhoria da qualidade da auditoria, entre eles o ceticismo profissional.

Segundo a Norma Brasileira de Contabilidade (NBC TA - R1 200, 2016) para a auditoria ser de qualidade é necessário que, durante a execução dos trabalhos, o auditor apresente um alto nível cético. Tal ceticismo, precisa se apresentar desde o processo de planejamento até a avaliação crítica das evidências encontradas para conclusão e emissão do parecer. Contudo, ainda que o ceticismo profissional seja reconhecido como essencial para reguladores e profissionais da contabilidade, o exercício de um nível suficiente de ceticismo pelos auditores continua sendo motivo de discussão global (PCAOB, 2013; CAQ, 2018; IAASB, 2018).

Por meio de uma carta pública, em 2018, o International Ethics Standards Board for Accountants (IESBA) levantou três principais pontos com relação ao ceticismo. O primeiro abordava as características comportamentais que afetam o ceticismo profissional. $\mathrm{O}$ segundo ponto trazia recomendações para que todos os profissionais contadores desenvolvessem e aplicassem tais características em seu trabalho. E o terceiro, recomendava que o Código de Ética Profissional dos contadores fosse atualizado, e que outras ações fossem desenvolvidas para lidar com o ceticismo profissional. Por fim, nessa consulta pública, mais de 62 organizações manifestaram suas opiniões, dentre elas o Center for Audit Quality (CAQ).

O CAQ ressaltou que as características comportamentais do ceticismo profissional vão além das análises de complexidades tecnológicas ou da globalização. Tratam-se de aspectos individuais como os traços de personalidade, habilidades individuais e incentivos recebidos. Características comportamentais como o ceticismo profissional, podem ser influenciadas por traços individuais dos auditores, como os traços de personalidade, que podem ser essenciais e refletir na prevenção de fraudes.

Haja visto que, quanto maior o traço cético, menores são as chances de fraudes passarem despercebidas durante o processo de auditoria das demonstrações contábeis (IAASB, 2018; Hurtt, Brown-Liburd, Earley \& Krishnamoorthy, 2013; Hurtt, 2010), as variáveis de personalidade podem apresentar um papel fundamental no estudo desta condição, para mitigar efeitos de falta de ceticismo. De forma mais ampla, o estudo da influência de traços de personalidade no ceticismo profissional é uma possibilidade para diagnosticar condições mais propensas a risco, bem como auxiliar no processo de avaliação de contratação de novos auditores pelas firmas de auditoria.

Os traços de personalidade podem ser divididos em cinco características individuais: extroversão, consciência, abertura à experiência, amabilidade e neuroticismo (McCrae \& John, 1992; Gosling, Rentfrow \& Swann, 2003). Tal divisão é conhecida na literatura como Big-Five, e é empregada por diversos estudos para investigar a relação dos traços de personalidade com o empreendedorismo (Antoncic, Kregar, Singh \& DeNoble, 2015), a satisfação no trabalho (Bui, 2017), as autoavaliações e ganhos (Williams \& Gardiner, 2018) e, o seu papel na determinação de conflitos e desempenho (Ayub, AlQurashi, Al-Yafi \& Jehn, 2017). 
De acordo com a literatura sobre o potencial reflexo dos traços de personalidade nos resultados alcançados pelos indivíduos, em consonância com à preocupação do International Auditing and Assurance Standards Board - IAASB (2018) em verificar como o ceticismo profissional pode ser aprimorado e, a orientação do CAQ (2018) em aprofundar o conhecimento sobre características comportamentais que podem afetar o ceticismo do auditor, o presente estudo propõe a discussão sobre a influência dos traços de personalidade no ceticismo profissional de auditores independentes. Segundo Farag e Elias (2016), é importante explorar as características de personalidade, porque tais traços podem impactar o comportamento dos indivíduos em uma organização.

Dado que o ceticismo profissional é uma característica individual multidimensional, necessária à qualidade da auditoria para minimizar as possibilidades de distorções relevantes causadas por erros ou fraudes e, considerando que os traços de personalidade podem refletir no comportamento dos indivíduos, elaborou-se a seguinte questão de pesquisa: Qual a influência dos traços de personalidade no ceticismo profissional de auditores independentes?

O estudo justifica-se pelo forte apelo dos órgãos normatizadores e reguladores para compreender os aspectos que podem influenciar o ceticismo profissional e como este reflete na qualidade da auditoria (PCAOB, 2013; NBC TA (R1) 200, 2016; IAASB, 2018; CAQ, 2018). O ceticismo, conforme Batista (2019) torna-se importante ao passo que visa:

[...] mitigar riscos e preservar o interesse público, dadas a deterioração do ambiente de negócios e a desonestidade de propósitos daqueles que buscam levar vantagens indevidas nas transações realizadas, motivadas por práticas criminosas em larga medida na lavagem de ativos, corrupção, crimes contra a ordem econômica, financeira e tributária, fraude em licitações, entre outros.

Além disso, o estudo busca atender a necessidade de compreensão das características individuais dos auditores que aprimoram a qualidade dos serviços prestados. O conhecimento dos traços comportamentais dos auditores é importante para o aperfeiçoamento de treinamentos e incentivos, objetivando a melhoria na qualidade da auditoria e, consequentemente, a detecção de erros e fraudes (IAASB, 2018). Por isso, verificar se e quais traços de personalidade do Big-Five influenciam o ceticismo profissional, é uma alternativa para melhorar a composição das equipes de auditoria e possibilitar melhores resultados na análise de evidências e emissão de opinião.

\section{CETICISMO PROFISSIONAL E OS TRAÇOS DE PERSONALIDADE}

O ceticismo profissional é amplamente difundido na auditoria, principalmente, no que tange à prevenção de fraudes contábeis. É importante para o auditor conciliar a característica cética com os princípios e normas éticas da contabilidade. Diversos órgãos reguladores como o IAASB, o American Institute of Certified Public Accountants (AICPA), o Public Company Accounting Oversight Board (PCAOB) e outros, definem o ceticismo profissional como uma atitude que inclui uma mente questionadora e alerta para condições que podem indicar possível distorção devido a um erro ou fraude e, uma avaliação crítica da evidência de auditoria.

Nelson (2009) destaca que o ceticismo profissional se refere a uma dúvida presuntiva sobre as evidências encontradas, de forma que as demonstrações financeiras estejam livres de distorções ou controles internos ineficientes. Para o autor supracitado, o ceticismo profissional em auditoria ocorre por meio da combinação do julgamento cético e da ação cética, devidamente sintetizado e explicado por Hurtt et al. (2013).

O julgamento cético ocorre quando um auditor reconhece que um possível problema pode existir e que mais trabalho ou esforço é necessário. Por sua vez, a ação cética ocorre quando um auditor muda seu comportamento com base no julgamento cético. Tanto o julgamento quanto a ação céticos são essenciais para a auditoria, sendo o julgamento cético uma condição necessária para a ação cética. A existência de ambos traduz numa maior probabilidade de ocorrerem ações profissionalmente céticas no trabalho do auditor (Hurtt et al., 2013).

Posteriormente a Nelson (2009), Hurtt (2010) desenvolveu um modelo composto por seis características pertinentes a um indivíduo cético, tornando possível averiguar o traço cético do profissional. As seis características são apresentadas na Tabela 1. 
Tabela 1. Características do Ceticismo Professional conforme Modelo de Hurtt (2010)

\begin{tabular}{ll}
\hline \multicolumn{1}{c}{ Característica } & \multicolumn{1}{c}{ Descrição } \\
\hline Mente questionadora & $\begin{array}{l}\text { Nível de questionamento ou dúvida sobre as informações obtidas para for-mação de suas } \\
\text { crenças durante o trabalho de auditoria. }\end{array}$ \\
Suspensão do julgamento & $\begin{array}{l}\text { Grau de julgamento que o auditor retém até que exista evidências suficientes que } \\
\text { corroborem suas conclusões. }\end{array}$ \\
Busca do conhecimento & $\begin{array}{l}\text { Intensidade do grau de procura por novos conhecimentos ou informações. } \\
\text { Entendimento interpessoal que o auditor possui em relação as evidências que encontra, } \\
\text { bonhecimento interpessoal como, do comportamento das pessoas. }\end{array}$ \\
Autoestima & $\begin{array}{l}\text { Grau de autoconfiança do indivíduo sobre si mesmo e sobre o que está inves-tigando, na } \\
\text { qual valoriza-se suas próprias percepções. } \\
\text { Gutonomia }\end{array}$ \\
\hline
\end{tabular}

Fonte: Elaborada com base em Hurtt (2010).

As três primeiras características da Tabela 1 referem-se ao comportamento de busca de evidências antes de tomar qualquer decisão. Ou seja, o auditor acaba por aguardar e ter evidências suficientes para poder fazer seu julgamento. A quarta característica, conhecimento interpessoal, são as experiências pessoais passadas que o auditor possui e que pode acessar no desenvolvimento de seu trabalho, inclusive no auxílio da identificação de indícios de fraudes. Por fim, a quinta e a sexta características, autoestima e autonomia, são pessoais dos indivíduos, necessárias na profissão da auditoria, pois fortalecem a construção do perfil cético deste profissional.

Destaca-se que a possibilidade de mensuração do ceticismo profissional por meio do modelo de Hurtt (2010) surgiu dez anos após os principais escândalos contábeis envolvendo firmas de auditoria em fraudes de demonstrações financeiras. Tal fato impulsionou o International Federation of Accountants (IFAC) requisitar à comunidade profissional discussões acerca da evolução da auditoria no mundo, sendo o ceticismo profissional um dos pontos evidenciados (IFAC, 2018). O IAASB, por meio de normas e diretrizes para os auditores, afirma que o ceticismo pode ser incentivado pelas firmas de auditoria, por meio da educação, de treinamentos e da própria experiência do auditor (IAASB, 2018).

Para desenvolver o ceticismo, a empresa de auditoria KPMG disponibiliza materiais para consulta, que podem aumentar as dimensões de julgamento e ceticismo profissional (Kwock, Ho, \& James, 2016). Todavia, os autores afirmam que não basta aplicar o treinamento para aumentar o nível de ceticismo profissional, pois esse também pode ser evidenciado como um traço. Portanto, faz-se necessário observar outros aspectos que podem influenciá-lo, como as características pessoais dos indivíduos, dentre elas os traços de personalidade (Hurtt et al., 2013; CAQ, 2018).

Pesquisas na área de psicologia empregam a estrutura Big-Five para identificar os traços de personalidade (Farag \& Elias, 2016). Essa estrutura contempla um modelo hierárquico de características de personalidade dividido em cinco dimensões, com objetivo de representar a personalidade do indivíduo em seu nível mais amplo de abstração (McCrae \& John, 1992; Gosling et al., 2003). Tais dimensões consistem em: abertura à experiência, consciência, extroversão, amabilidade/afabilidade e neuroticismo.

A dimensão de abertura à experiência, representa indivíduos particularmente reflexivos, curiosos, abertos a novas experiências e novidades (McCrae \& Costa, 1997; Gosling et al., 2003). A predominância desse traço de personalidade indica indivíduos receptivos aos sinais do ambiente, tendenciosos a maior atenção nas oportunidades, prevenidos, perspicazes e perceptivos (Antoncic, Kregar, Singh \& Denoble, 2015), além de melhor capacidade para o processamento de informações incompletas (Denissen \& Penke, 2008).

Diante dessas características, espera-se que a abertura à experiência tenha uma relação positiva com o ceticismo profissional de auditores, dado o entendimento de que indivíduos mais reflexivos e curiosos tendem a possuírem elevado nível de ceticismo profissional. Nesse contexto, formula-se a primeira hipótese do estudo:

$\mathbf{H}_{1}$ : Há influência positiva do traço de personalidade de abertura à experiência no ceticismo profissional de auditores independentes. 
A predominância do traço de consciência caracteriza indivíduos autoguiados e orientados para o alcance de objetivos (Judge \& Ilies, 2002). Trata-se de indivíduos organizados, responsáveis e autodisciplinados (Gosling et al., 2003). Esses indivíduos são considerados competentes, obedientes, disciplinados, cautelosos, confiáveis e confiantes (Mckee, Waples, \& Tullis, 2017). Entende-se que a predominância desse traço de personalidade seja positivamente relacionada ao ceticismo profissional de auditores, pois de acordo com Steel (2007), indivíduos com traço de consciência procuram realizar seus trabalhos da melhor maneira possível, demonstrando-se convergente com o ceticismo profissional. Assim, apresenta-se a segunda hipótese de pesquisa: independentes.

$\mathbf{H}_{2}$ : Há influência positiva do traço de personalidade da consciência no ceticismo profissional de auditores

A extroversão está presente em indivíduos com alta amabilidade, ou seja, pessoas entusiasmadas, falantes e ativas (Gosling et al., 2003). Indivíduos com alta pontuação nessa dimensão tendem a serem bem-humoradas e empáticos (Gosling et al., 2003). Um indivíduo com esse traço predominante concentra-se de forma mais acentuada em elementos externos que estão sob sua influência. São considerados amigáveis, sociáveis, impulsivos, descuidados e flexíveis, com pouca preocupação em relação ao futuro, com ambição reduzida e limitado autocontrole (Sadi, Asl, Rostami, Gholipour, \& Gholipour, 2011). Nessa pesquisa a extroversão recebe um enfoque correspondente as suas influências negativas, como o comportamento impulsivo, descuidado, flexíveis e limitado autocontrole, o que sugere que indivíduos com predominância desse traço de personalidade tendem a apresentarem menor ceticismo profissional, no qual tem-se a terceira hipótese: independentes.

$\mathbf{H}_{3}$ : Há influência negativa do traço de personalidade de extroversão no ceticismo profissional de auditores

A dimensão amabilidade/afabilidade representa a tendência da forma de tratamento que o indivíduo tem com o outro (Costa \& McCrae, 1992). São pessoas confiantes, cooperativas, amáveis, gentis, calorosas, sensíveis a questões normativas, procuram ter bons relacionamentos com os outros e que contribuem com o bem-estar social (Ko, Chang, Jang, Sagas \& Spengler, 2016; Moghavvemi, Woosnam, Paramanathan, Musa \& Hamzah, 2017). Ademais, representa um grau de submissão a outros indivíduos (Gosling et al., 2003) e podem agir frequentemente de maneira impensada e impulsiva, movidos pelo sentimento (Antoncic, Kregar, Singh, \& Denoble, 2015). Entendese que a predominância de amabilidade, gentileza e com tendência de bons relacionamentos, é um contraponto ao nível de ceticismo profissional justamente pela necessidade de manter tal perfil de sociabilidade. Então apresentase a quarta hipótese do estudo:

$\mathbf{H}_{4}$ : Há influência negativa do traço de personalidade de amabilidade no ceticismo profissional de auditores independentes.

Por fim, tem-se os indivíduos com predominância de neuroticismo, ou seja, indivíduos com grau de instabilidade emocional (Gosling et al., 2003). Esse traço apresenta características de angústia, frustação, aflição e desespero (Ko et. al., 2016). Indivíduos com alto neuroticismo geralmente são egoístas e egocêntricos, almejam superioridade no que fazem, e possuem necessidade de serem elogiados por terceiros (Sadi et al., 2011). Borghans et al., (2008) enfatizam que o indivíduo com tal predominância se destaca pela impulsividade, o que destoa das características de um indivíduo com elevado nível de ceticismo profissional, surgindo a quinta hipótese deste estudo:

$\mathbf{H}_{5}$ : Há influência negativa do traço de personalidade do neuroticismo no ceticismo profissional de auditores independentes.

\section{PROCEDIMENTOS METODOLÓGICOS}

\subsection{População e amostra}

A população comtempla os auditores independentes brasileiros listados no Cadastro Nacional de Auditores Independentes (CNAI) do Conselho Federal de Contabilidade (CFC). Inicialmente buscou-se pelos auditores registrados no CNAI com perfis ativos na rede de contatos profissionais LinkedIn ${ }^{\circledR}$. A busca e envio das solicitações de conexão compreendeu o período de 30 de novembro de 2018 a 06 de janeiro de 2019, enquanto a coleta dos dados estendeu-se até 30 de janeiro de 2019. 
Do total de 3.877 auditores com registro ativo no CNAI até 30 de novembro de 2018, foi utilizada uma amostra inicial de 2.236 auditores, decorrente dos perfis profissionais localizados, correspondendo a $58 \%$ dos profissionais cadastrados no Brasil. A composição da final da amostra é de 321 auditores, que participaram da pesquisa, contemplando todas as regiões do país.

\subsection{Variáveis da pesquisa e técnica de coleta de dados}

Para o desenvolvimento deste estudo foi utilizado o questionário apresentado no Apêndice A. Em tal questionário, a variável CP (ceticismo profissional) contemplou as características de Hurtt (2010), abordadas em 30 questões, já validadas no Brasil, sendo 5 questões para cada uma das seis características. Todas foram mensuradas por meio de uma escala do tipo likert de 6 pontos. A escala total (soma da pontuação de todas as dimensões) varia de 30 a 180 pontos, sendo que quanto mais próximo de 180 maior é o nível de ceticismo. Hurtt (2010) não estabelece uma classificação quanto ao nível de ceticismo profissional, entretanto, menciona que acima de 126 pontos $(70 \%)$ já se tem um entendimento de elevado nível de ceticismo profissional.

As variáveis para os traços de personalidade foram mensuradas considerando a estrutura do Big-Five, ou seja, divididas em cinco dimensões, por meio do instrumento denominado Ten Item of Personality Intentory (em português, Inventário de Dez Itens de Personalidade), também conhecido como modelo de Gosling et al. (2003), validado no Brasil. Tal modelo é composto por 10 questões, mensuradas por uma escala likert de 5 pontos, sendo 2 questões para cada dimensão. A soma das duas questões em sua dimensão pode totalizar no mínimo 2 e no máximo 10 pontos. Destaca-se que a escala reduzida de mensuração possui a mesma qualidade de observação das escalas originais (Gosling et al., 2003).

Para a coleta de dados, foi enviado aos auditores um link de acesso ao questionário eletrônico (https://bit. 1y/2QxZoBD), o qual foi estruturado com perguntas de caracterização dos respondentes, experiência profissional e da firma de auditoria, as 30 questões para mensuração do ceticismo profissional e as 10 para os traços de personalidade, de acordo com os constructos propostos para a pesquisa.

\subsection{Análise dos dados}

Para as análises, adotou-se estatística descritiva, testes de normalidade e regressão linear múltipla, conforme Equação 1.

$$
C P=\beta_{0}+\beta_{1} A E+\beta_{2} C+\beta_{3} E+\beta_{4} A+\beta_{5} N+\varepsilon
$$

Em que:

$C P$ : corresponde ao nível de ceticismo profissional;

$\beta_{0}$ : corresponde ao intercepto;

$A E$ : Traço de personalidade abertura à experiência;

$C$ : Traço de personalidade consciência;

$E$ : Traço de personalidade extroversão;

$A$ : Traço de personalidade amabilidade/afabilidade;

$N$ : Traço de personalidade neuroticismo;

$\beta_{1}$ ao $\beta_{5}$ : correspondem aos coeficientes para cada variável apresentada

$\varepsilon$ : erro de termo aleatório.

A Equação 1 foi utilizada de forma segregada para os auditores pertencentes a firmas de auditoria Big Four e não Big Four. O objetivo de segregar pelo formato de firma surge da evidência de estudos anteriores como, por exemplo, Bamber, Snowball e Tubbs (1989), que sugere a existência de diferenças nas relações entre características organizacionais para ambas as estruturas de firmas de auditoria. Para a estimação dos modelos foi utilizada a técnica de regressão linear múltipla pelo método dos mínimos quadrados (Ordinary Least Squares). 


\section{ANÁLISE E DISCUSSÃO DOS RESULTADOS}

Realizou-se uma análise descritiva das variáveis relacionadas a caracterização dos auditores, das características do ceticismo profissional e dos traços de personalidade, apresentados na Tabela 2.

Tabela 2. Estatística descritiva

\begin{tabular}{|c|c|c|c|c|c|}
\hline \multicolumn{6}{|c|}{ Painel A: Caracterização dos respondentes } \\
\hline Sexo & $\mathrm{n}$ & $\%$ & Tipo de Firma & n & $\%$ \\
\hline \multirow{2}{*}{ Feminino } & \multirow{2}{*}{88} & \multirow{2}{*}{27,41} & Big Four & 58 & 65,91 \\
\hline & & & Não Big Four & 30 & 34,09 \\
\hline \multirow{2}{*}{ Masculino } & \multirow{2}{*}{233} & \multirow{2}{*}{72,59} & Big Four & 116 & 49,79 \\
\hline & & & Não Big Four & 117 & 50,21 \\
\hline \multicolumn{6}{|c|}{ Painel B: Estatística descritiva do ceticismo profissional e dos traços de personalidade } \\
\hline & Dimensão & Média & Desvio Padrão & Mediana & Moda \\
\hline \multirow{7}{*}{$\begin{array}{l}\text { Ceticismo } \\
\text { profissional }\end{array}$} & Mente questionadora & 24,44 & 3,57 & 25,00 & 25,00 \\
\hline & Suspensão do julgamento & 22,69 & 4,09 & 23,00 & 25,00 \\
\hline & Busca pelo conhecimento & 27,92 & 2,91 & 29,00 & 30,00 \\
\hline & Compreensão interpessoal & 23,56 & 4,87 & 25,00 & 30,00 \\
\hline & Autoestima & 26,22 & 4,04 & 27,00 & 30,00 \\
\hline & Autonomia & 23,60 & 3,67 & 24,00 & 25,00 \\
\hline & Ceticismo Profissional $=\Sigma$ & 148,43 & 12,46 & 149,00 & 159,00 \\
\hline \multirow{5}{*}{$\begin{array}{c}\text { Traços de } \\
\text { personalidade }\end{array}$} & Abertura à experiência & 6,67 & 1,94 & 7,00 & 8,00 \\
\hline & Consciência & 7,94 & 1,54 & 8,00 & 8,00 \\
\hline & Extroversão & 8,08 & 1,42 & 8,00 & 8,00 \\
\hline & Amabilidade & 5,68 & 1,09 & 6,00 & 6,00 \\
\hline & Neuroticismo & 7,25 & 1,78 & 7,00 & 7,00 \\
\hline
\end{tabular}

Fonte: Dados da pesquisa.

Observa-se pelos resultados no Painel A que dos 321 auditores, 88 (27,41\%) são mulheres e $233(72,59 \%)$ são homens, alinhado a um perfil percebido em auditoria. Sendo que a maior participação de mulheres na auditoria está em firmas Big Four.

No Painel B, constata-se que o grupo apresentou média e mediana próximas e, ainda que se considere os desvios padrões, os resultados demonstraram nível elevado de ceticismo, ou seja, acima de 70\%. Destaque para a característica busca pelo conhecimento, que no modelo de Hurtt (2010) corresponde a dimensão de avaliação de evidências relacionando-se com a forma como a prova é examinada, indicando a vontade de procurar e examinar provas suficientes antes de tomar uma decisão. Níveis altos nessa dimensão indica profissionais altamente engajados, que se preocupam em alcançar quantidade suficiente de conhecimento para tomar suas decisões.

Destaca-se também na pontuação média a autoestima, indicando uma capacidade de o indivíduo agir sobre a informação obtida e demonstrar um grau de autoconfiança sobre si mesmo, o qual representa o quanto este valoriza suas próprias percepções (Hurtt, 2010). Por outro lado, a variável suspensão de julgamento obteve a menor pontuação média $(22,69)$. Tal dimensão representa a interrupção de um julgamento até que o auditor possua as evidências adequadas para a conclusão do trabalho (Hurtt, 2010).

De modo complementar, realizou-se o teste de diferenças entre médias para o nível de ceticismo profissional dos auditores em dois grupos de análise: (i) quanto ao sexo e, (ii) quanto ao tipo da firma de auditoria. Os resultados são demonstrados na Tabela 3.

Tabela 3. Resultado do teste de diferenças entre médias para o nível de ceticismo profissional

\begin{tabular}{cccccc}
\hline \multirow{2}{*}{ Grupos } & \multicolumn{3}{c}{ Teste de Levene } & \multicolumn{3}{c}{ Teste-T } \\
\cline { 2 - 5 } & $\mathrm{F}$ & Sig. & Estatística t & Sig. & Diferença média \\
\hline Sexo & 1,393 & 0,239 & $-0,316$ & 0,752 & $-0,494$ \\
Firma & 1,335 & 0,249 & 0,240 & 0,810 & 0,336 \\
\hline
\end{tabular}

Fonte: Dados da pesquisa.

Nota: *. p-value significativo $(\mathrm{p}<0,05)$. 
Os resultados para o Teste de Levene demonstram um p-value não significativo, ou seja, o pressuposto de igualdade de variâncias foi respeitado para os dois grupos de teste. O mesmo acontece para os resultados do Teste-T, no qual conclui-se que não se pode dizer que há diferenças estatísticas entre os grupos. Desse modo, as evidências indicam que não existem diferenças no traço cético entre homens e mulheres e tampouco com relação ao porte da firma de auditoria, demonstrando que os dados podem ser analisados em conjunto.

De forma a assegurar a validade dos dados coletados e assegurar os resultados obtidos, os resíduos da regressão foram submetidos ao teste de Kolmogorov-Smirnov (K-S), que apresentou p-value superior a 5\%, aceitando-se a hipótese de que a distribuição dos resíduos é normal. O teste de multicolinearidade comprovou, por meio do resultado de Tolerance e VIF, que as variáveis não possuem problemas de multicolinearidade em nenhum dos modelos testados. Então, os resultados indicam modelos estatisticamente significativos, como apresentado na Tabela 4.

Tabela 4. Influência dos traços de personalidade no ceticismo profissional

\begin{tabular}{|c|c|c|c|c|c|c|c|}
\hline $\begin{array}{c}\text { Variável } \\
\text { independente }\end{array}$ & $\begin{array}{c}\beta \text { Não } \\
\text { Padronizado }\end{array}$ & $\begin{array}{c}\boldsymbol{\beta} \\
\text { Padronizado }\end{array}$ & t-statistic & Sig. & VIF & $\mathbf{R 2}$ & $\begin{array}{l}\text { Durbin- } \\
\text { Watson }\end{array}$ \\
\hline \multicolumn{8}{|c|}{ Painel A: Resultados do modelo com todos os auditores $(\mathrm{n}=321)$} \\
\hline Ceticismo profissional & 123,456 & & 20,530 & $0,000 * * *$ & & \multirow{6}{*}{0,220} & \multirow{6}{*}{1,839} \\
\hline Abertura à experiência & 2,291 & 0,252 & 4,703 & $0,000 * * *$ & 1,164 & & \\
\hline Consciência & 1,728 & 0,209 & 3,967 & $0,000 * * *$ & 1,121 & & \\
\hline Extroversão & 0,515 & 0,080 & 1,460 & 0,145 & 1,207 & & \\
\hline Amabilidade & $-2,865$ & $-0,245$ & $-4,486$ & $0,000 * * *$ & 1,208 & & \\
\hline Neuroticismo & 0,761 & 0,107 & 2,035 & $0,043 * *$ & 1,124 & & \\
\hline \multicolumn{8}{|c|}{ Painel B: Resultados do modelo para as firmas Big Four $(\mathrm{n}=174)$} \\
\hline Ceticismo profissional & 126,432 & & 15,680 & $0,000 * * *$ & & \multirow{6}{*}{0,232} & \multirow{6}{*}{1,923} \\
\hline Abertura à experiência & 1,883 & 0,215 & 2,990 & $0,003 * * *$ & 1,130 & & \\
\hline Consciência & 1,947 & 0,249 & 3,542 & $0,001 * * *$ & 1,082 & & \\
\hline Extroversão & 0,927 & 0,149 & 2,011 & $0,046^{* *}$ & 1,195 & & \\
\hline Amabilidade & $-3,343$ & $-0,281$ & $-3,843$ & $0,000 * * *$ & 1,167 & & \\
\hline Neuroticismo & 0,698 & 0,106 & 1,495 & 0,137 & 1,097 & & \\
\hline \multicolumn{8}{|c|}{ Painel C: Resultados do modelo para as firmas não Big Four $(n=147)$} \\
\hline Ceticismo profissional & 117,060 & & 12,441 & $0,000 * * *$ & & \multirow{6}{*}{0,239} & \multirow{6}{*}{1,928} \\
\hline Abertura à experiência & 2,967 & 0,309 & 3,768 & $0,000 * * *$ & 1,249 & & \\
\hline Consciência & 1,476 & 0,164 & 2,025 & $0,045 * *$ & 1,217 & & \\
\hline Extroversão & 0,114 & 0,017 & 0,209 & 0,835 & 1,231 & & \\
\hline Amabilidade & $-2,407$ & $-0,210$ & $-2,537$ & $0,012 * *$ & 1,269 & & \\
\hline Neuroticismo & 0,995 & 0,125 & 1,589 & 0,114 & 1,146 & & \\
\hline
\end{tabular}

Fonte: Dados da pesquisa.

Nota: *. Significância no nível 0,$10 ; * * 0,05 ; * * * 0,01$.

Observa-se que os resultados em todos os painéis apresentaram um poder de explicação $\left(\mathrm{R}^{2}\right)$ igual ou superior de $22 \%$, ou seja, os traços de personalidade têm um poder de explicação de no mínimo $22 \%$ do ceticismo dos auditores. Além disso, diversas variáveis apresentaram-se significantes a 1\%, sendo inexistente a presença de autocorrelação dos resíduos.

No Painel A, em que são considerados todos os auditores, dentre os traços de personalidade testados com o ceticismo profissional somente a extroversão não foi significativa. Além de apresentar sinal contrário ao esperado, assim como o neuroticismo, que apesar de mostrar uma relação significativa, apresentou sinal positivo. Dessa forma, considerando todos os auditores da amostra, as hipóteses 1, 2 e 4 foram confirmadas, indicando existência de relações entre os traços de personalidade, abertura à experiência, consciência e amabilidade com o ceticismo profissional. 
O resultado encontrado no Painel B, considera somente os auditores das firmas Big Four e apresentou resultados semelhantes ao Painel A, com poder explicativo de 23,2\%. Entretanto, nesse grupo de auditores, o traço de neuroticismo não se mostrou significativo e, o traço de extroversão foi significativo, ambos com sinais contrários aos esperados.

Para os auditores de firmas de auditoria não Big Four os resultados mostram-se semelhantes aos painéis anteriores. Nesse caso, a extroversão e o neuroticismo não foram significantes. Os resultados dos Painéis B e C confirmam os resultados do Painel A quanto a aceitação das hipóteses 1, 2 e 4.

Os resultados apresentam novas evidências a literatura acerca dos traços de personalidade. No que se refere a hipótese 1, observa-se a influência positiva entre o traço de abertura a experiência e o ceticismo profissional. Dado que o principal conceito de ceticismo, atribuído por órgãos reguladores, refere-se a uma mente questionadora e alerta para condições que indiquem possível distorção por erro ou fraude e, que a abertura a experiência se refere a um indivíduo reflexivo, curioso, perceptivo (McCrae \& Costa, 1997; Gosling et al., 2003). A relação entre as variáveis se mostra adequada para que o auditor tenha condições de conduzir todo o processo de auditoria de forma cética e alerta para qualquer indício de distorção ou fraudes.

A hipótese 2, que trata da influência positiva do traço de personalidade consciência - característica de indivíduos autoguiados, orientados em metas (Judge \& Ilies, 2002), organizados, responsáveis e autodisciplinados (Gosling et al., 2003), competentes, obedientes, cautelosos, confiáveis e confiantes (Mckee, Waples, \& Tullis, 2017) -, sobre o ceticismo profissional também foi confirmada. A consciência tende a apresentar alinhamento com algumas características pertinentes de ceticismo profissional, quais são: autoestima, suspensão de julgamento e conhecimento interpessoal.

A confirmação da hipótese 4 indica que há influência negativa do traço de personalidade amabilidade no ceticismo profissional. Conforme definido na literatura, a amabilidade indica característica de gentileza e com tendência a bons relacionamentos (Ko et al., 2016; Moghavvemi et al., 2017). Por isso, indivíduos amáveis podem apresentar um nível de ceticismo profissional menor, justamente pela necessidade de manter tal perfil. Ter um ceticismo profissional elevado denota uma mente questionadora e alerta que pode caracterizar desconfiança perante o auditado.

Os resultados encontrados, ao relacionar os traços de personalidade com o ceticismo profissional de auditores independentes, mostraram-se congruentes aos de Farag e Elias (2016) - ao investigarem a relação com alunos de graduação em contabilidade. Os resultados desta pesquisa são as primeiras evidências nacionais sobre a influência dos traços de personalidade Big-Five, de McCrae e John (1992) e Gosling et al. (2003), no traço cético de auditores, de que temos conhecimento. Esses resultados são particularmente importantes dada a extensão das discussões sobre a qualidade da auditoria na literatura e a necessidade de elevado nível de ceticismo profissional em todo o processo de auditoria.

Além das discussões do ceticismo profissional exigido pelas normas, as características de personalidade acrescentam uma visão mais individual dos resultados apresentados, visto que, a análise conjunta dos resultados permite discutir um panorama nacional e ressalta a necessidade de uma visão que vai além de normas e padrões profissionais a serem seguidos. Os resultados ainda se alinham as intenções do IESBA (2018) do Center for Audit Quality (2018) ao apresentar resposta ao ponto de identificar quais características comportamentais do auditor afetam o ceticismo profissional.

\section{CONCLUSÕES}

Este estudo verificou a influência dos traços de personalidade no ceticismo profissional de auditores independentes com registro ativo no CNAI (2018). A população limitou-se aos auditores independentes com perfis ativos na rede de contatos profissionais LinkedIn ${ }$. O instrumento de pesquisa foi estabelecido com base no estudo de Hurtt (2010) e Gosling et al. (2003), sendo constuído um questionário que posteriormente foi encaminhado para 2.236 auditores independentes ativos no Linkedin $\AA$. A amostra correspondeu a um total 321 questionários considerados válidos na pesquisa.

Constatou-se que os traços de personalidade apresentados por Gosling et al. (2003) explicam conjuntamente $22 \%$ do ceticismo profissional dos auditores analisados. As dimensões de abertura à experiência e consciência apresentaram relação positiva e significativa com o ceticismo profissional. Enquanto, a amabilidade apresentou relação negativa com o ceticismo dos auditores da amostra. Tais resultados vão ao encontro do que foi proposto nas hipóteses de pesquisa, sustentadas pela literatura dos temas. 
As dimensões de extroversão e neuroticismo apresentaram resultados divergentes aos observados na literatura. Esses resultados foram encontrados quando analisados de forma segregada os auditores de firmas Big Four e não Big Four, bem como quando analisados de forma agregada.

Os resultados sinalizam aos órgãos reguladores, auditores e firmas de auditoria que o ceticismo profissional resulta de uma função de traços de personalidade individuais, entre outros fatores. Assim, observar os traços de personalidade dos auditores pode contribuir para entender o comportamento cético durante o processo de auditoria.

Os achados mostram-se importantes ao passo que, mapear o traço de personalidade na composição da equipe de auditoria, pode refletir positivamnte na qualidade do trabalho desenvolvido posteriormente. Uma vez que a equipe apresentará comportamento cético, ou seja, livres de distorção relevantes causadas por erros ou fraudes.

Como limitação da pesquisa, destaca-se que não foram controladas outras variáveis comportamentais, as quais poderiam influenciar nos resultados desta e de outras pesquisas como, por exemplo, o estresse. O período de coleta também pode ser considerado uma limitação, visto que a mesma ocorreu nos meses de dezembro de 2018 a janeiro de 2019, período de alta demanda de trabalho e fechamento das demonstrações contábeis das firmas auditadas. Novas pesquisas, podem explorar outras variáveis comportamentais que influenciam o ceticismo profissional e os outros fatores relevantes para o comportamento cético.

\section{REFERÊNCIAS}

Antoncic, B., Bratkovic Kregar, T., Singh, G., \& DeNoble, A. F. (2015). The Big-Five personality-entrepreneurship relationship: evidence from Slovenia. Journal of Small Business Management, 53(3), 819-841. DOI: https:// doi.org/10.1111/jsbm.12089.

Ayub, N., AlQurashi, S. M., Al-Yafi, W. A., \& Jehn, K. (2017). Personality traits and conflict management styles in predicting job performance and conflict. International Journal of Conflict Management, 28(5), 671-694. DOI: 10.1108/IJCMA-12-2016-0105.

Batista, S. (2019). O ceticismo professional na Contabilidade e a mitigação de risco. Disponível em: $<$ https://cfc. org.br/destaque/o-ceticismo-profissional-na-contabilidade-e-a-mitigacao-de-risco/>. Acesso em: 30 de jun. de 2019.

Beasley, M. S., Carcello, J. V., \& Hermanson, D. R. (2001). Top 10 audit deficiencies. Journal of Accountancy, $19(1), 63$.

Borghans, L., Duckworth, A. L., Heckman, J. J., \& Weel, B. (2008). The Economics and Psychology of Personality Traits. Journal of Human Resources, 43(4), p. 972-1059. DOI:10.3368/jhr.43.4.972.

Bui, H. T. (2017). Big-Five personality traits and job satisfaction: Evidence from a national sample. Journal of General Management, 42(3), 21-30. DOI: 10.1177/0306307016687990.

Center for Audit Quality (CAQ). (2018). Invitation to Comment, Professional Skepticism - Meeting Public Expectations. Disponível em: <https://www.thecaq.org/wp-content/uploads/2019/03/caq_comment_iesba_ prof_skepticism_meeting_public_expectations_2018-08.pdf $>$. Acesso em: 07 de jan. de 2019.

Conselho Federal de Contabilidade, C. F.C (2016). Resolução CFC NBC TA 200 (R1), de 19 de agosto de 2016. Altera a NBC TA 200 que dispõe sobre os objetivos gerais do auditor independente e a condução da auditoria em conformidade com normas de auditoria. Brasília, DF.

Costa, P. T., \& McCrae, R. R. (1992). Revised NEO personality inventory (NEO-PI-R) and NEO five-factor (NEOFFI) inventory professional manual. Odessa, FL: Psychological Assessment Resources.

Denissen, J. J., \& Penke, L. (2008). Motivational individual reaction norms underlying the Five-Factor model of personality: First steps towards a theory-based conceptual framework. Journal of research in personality, 42(5), 1285-1302. DOI: https://doi.org/10.1016/j.jpp.2008.04.002.

Farag, M. S., \& Elias, R.Z.(2016). The relationship between accounting students'personality, professional skepticism and anticipatory socialization. Accounting Education, 25(2), 124-138. DOI: 10.1080/09639284.2015.1118639.

Gosling, S. D., Rentfrow, P. J., \& Swann Jr, W. B. (2003). A very brief measure of the Big-Five personality domains. Journal of Research in personality, 37(6), 504-528. DOI: 10.1016/S0092-6566(03)00046-1.

Hurtt, R. K. (2010). Development of a scale to measure professional skepticism. Auditing: A Journal of Practice \& Theory, 29(1), 149-171. DOI: 10.2308/aud.2010.29.1.149. 
Hurtt, R. K., Brown-Liburd, H., Earley, C. E., \& Krishnamoorthy, G. (2013). Research on auditor professional skepticism: Literature synthesis and opportunities for future research. Auditing: A Journal of Practice \& Theory, 32(sp1), 45-97. DOI: 10.2308/ajpt-50361.

International Auditing and Assurance Standards Board (IAASB). (2018). Professional Skepticism in an Audit of Financial Statements. Disponível em: <https:/www.iaasb.org/system/files/meetings/files/20150615-iaasbagenda_item_10-c-iaasb_professional_skepticism_staff_qanda-final.pdf $>$. Acesso em: 07 de jan. de 2019.

International Federation of Accountants (IFAC). KPMG IFRG Limited (2018) Invitation to Comment, Professional Skepticism - Meeting Public Expectations. Disponível em: <http://www.ifac.org/system/files/publications/ exposuredrafts/comments/KPMGResponsetoCP_ProfessionalSkepticism-MeetingPublicExpectations.pdf> Acesso em: 06 de jan. de 2019.

Judge, T. A., \& Ilies, R. (2002). Relationship of personality to performance motivation: A meta-analytic review. Journal of applied psychology, 87(4), 797. DOI: 10.1037//0021-9010.87.4.797.

Ko, Y. J., Chang, Y., Jang, W., Sagas, M., \& Spengler, J. O. (2016). A Hierarchical Approach for Predicting Sport Consumption Behavior: A Personality and Needs Perspective. Journal of Sport Management, 31(3), p. 213228. DOI: $10.1123 /$ jsm.2015-0142.

Kwock, B., Ho, R., \& James, M. (2016). The effectiveness of professional scepticism training for auditors in China: evidence from a university in China. China Journal of Accounting Studies, 4(2), 205-224.DOI: https:// doi.org/10.1080/21697213.2016.1196055.

McCrae, R. R., \& Costa, P. T. (1997). Conceptions and correlates of openness to experience. In Handbook of personality psychology (pp. 825-847). DOI: 10.1016/B978-012134645-4/50032-9.

McCrae, R. R., \& John, O. P. (1992). An introduction to the five-factor model and its applications. Journal of personality, 60(2), 175-215. DOI: 10.1111/j.1467-6494.1992.tb00970.x.

McKee, V., Waples, E. P., \& Tullis, K. J. (2017). A Desire for the Dark Side: An Examination of Individual Personality Characteristics and Their Desire for Adverse Characteristics in Leaders. Organization Management Journal, 14(2), 104-115. DOI: https://doi.org/10.1080/15416518.2017.1325348.

Moghavvemi, S., Woosnam, K. M., Paramanathan, T., Musa, G., \& Hamzah, A. (2017). The effect of residents' personality, emotional solidarity, and community commitment on support for tourism development. Tourism Management, 63(1), p. 242-254. DOI: https://doi.org/10.1016/j.tourman.2017.06.021.

Nelson, M. W. (2009). A model and literature review of professional skepticism in auditing. Auditing: A Journal of Practice \& Theory, 28(2), 1-34. DOI: 10.2308/aud.2009.28.2.1.

PricewaterhouseCoopers (PwC) (2018). Tirando a fraude das sombras: pesquisa global sobre fraudes e crimes econômicos. Disponível em: < https://www.pwc.com.br/pt/estudos/assets/2018/gecs-18.pdf>. Acesso em: 01 de jul. de 2019.

Public Company Accounting Oversight Board (PCAOB). (2013). Auditor Objectivity and Skepticism: What's Next? Disponível em: https://pcaobus.org//News/Speech/Pages/03212012_HarrisStatement.aspx. Acesso em: 01 de jul. de 2019.

Sadi, R., Asl, H. G., Rostami, M. R., Gholipour, A., \& Gholipour, F. (2011). Behavioral Finance: The Explanation of Investors' Personality and Perceptual Biases Effects on Financial Decisions. International Journal of Economics and Finance, 3(5), p. 234-241. DOI: 10.5539/ijef.v3n5p234.

Steel, P. (2007). The nature of procrastination: A meta-analytic and theoretical review of quintessential selfregulatory failure. Psychological bulletin, 133(1), 65-94. DOI: 10.1037/0033-2909.133.1.65.

Williams , M., \& Gardiner, E. (2018). The power of personality at work: Core self-evaluations and earnings in the United Kingdom. Human Resource Management Journal, 28(1), 45-60. DOI: 10.1111/1748-8583.12162.

\section{Como citar este artigo}

Cunha, P. R. da, Silva, C. T. da, Peyerl, D. A. \& Haveroth, J. (2019). Influência dos traços de personalidade no ceticismo profissional de auditores independentes. Revista de Contabilidade e Organizações, 13:e158537. DOI: http://dx.doi.org/10.11606/issn.1982-6486.rco.2019.158537 
APÊNDICE A

INSTRUMENTO DE PESQUISA ELETRÔNICO

\section{Bloco 1 - Características do respondente, experiência profissional e da firma de auditoria}

\begin{tabular}{|c|c|c|c|}
\hline 1 & \multicolumn{3}{|l|}{ Qual sua idade? (Responder em anos) } \\
\hline 2 & \multicolumn{3}{|l|}{ Qual seu sexo? ( ) Feminino ( ) Masculino } \\
\hline 3 & $\begin{array}{l}\text { Qual sua formação acadêmica? (Considerando } \\
\text { toda a sua trajetória acadêmica, indique, no campo } \\
\text { abaixo a sua maior titulação) }\end{array}$ & \multicolumn{2}{|c|}{$\begin{array}{l}\text { ( ) Ensino Superior ( ) Especialização } \\
\text { ( ) Mestrado ( ) Doutorado ( ) Outra (especifique) }\end{array}$} \\
\hline 4 & $\begin{array}{l}\text { Com relação a pergunta anterior (3), especifique a } \\
\text { área de formação de sua maior titulação }{ }^{1}\end{array}$ & $\begin{array}{l}\text { ( ) Administração } \\
\text { ( ) Ciências Contábeis } \\
\text { ( ) Ciências Econômica } \\
\text { ( ) Ciências Jurídicas } \\
\text { ( ) Engenharia } \\
\text { ( ) Outra (especifique) }\end{array}$ & \\
\hline 5 & Em qual estado do Brasil você vive atualmente? & $\begin{array}{l}\text { ( ) Acre } \\
\text { ( ) Amapá } \\
\text { ( ) Bahia } \\
\text { ( ) Distrito Federal } \\
\text { ( ) Goiás } \\
\text { ( ) Mato Grosso } \\
\text { ( ) Minas Gerais } \\
\text { ( ) Paraíba } \\
\text { ( ) Pernambuco } \\
\text { ( ) Rio de Janeiro } \\
\text { ( ) Rio Grande do Sul } \\
\text { ( ) Roraima } \\
\text { ( ) São Paulo } \\
\text { ( ) Tocantins }\end{array}$ & $\begin{array}{l}\text { ( ) Alagoas } \\
\text { ( ) Amazonas } \\
\text { ( ) Ceará } \\
\text { ( ) Espírito Santo } \\
\text { ( ) Maranhão } \\
\text { ( ) Mato Grosso do Sul } \\
\text { ( ) Pará } \\
\text { ( ) Paraná } \\
\text { ( ) Piauí } \\
\text { ( ) Rio Grande do Norte } \\
\text { ( ) Rondônia } \\
\text { ( ) Santa Catarina } \\
\text { ( ) Sergipe }\end{array}$ \\
\hline $6 a$ & $\begin{array}{l}\text { Você possui o Cadastro Nacional de Auditores } \\
\text { Independentes (CNAI) }{ }^{2} \text { ? }\end{array}$ & ( ) $\operatorname{Sim}$ ( ) Não & \\
\hline $6 \mathrm{~b}$ & Atualmente você trabalha com auditoria? & ( ) $\operatorname{Sim}($ ) Não & \\
\hline 7 & Há quanto tempo você trabalha com auditoria? (Res & onder em anos) & \\
\hline 8 & Qual cargo você ocupa nessa firma? & $\begin{array}{l}\text { ( ) Auditor Trainee } \\
\text { ( ) Supervisor/Gerente } \\
\text { ( ) Auditor Sócio }\end{array}$ & $\begin{array}{l}\text { ( ) Auditor Assistente } \\
\text { ( )Auditor Sênior } \\
\text { ( ) Outra (especifique) }\end{array}$ \\
\hline 9 & A firma de auditoria faz parte do grupo Big Four? & ( ) $\operatorname{Sim}($ ) Não & \\
\hline 10 & $\begin{array}{l}\text { Em qual Estado da região do Brasil, localiza-se a } \\
\text { sede da firma de auditoria na qual você atua? }\end{array}$ & $\begin{array}{l}\text { ( ) Acre } \\
\text { ( ) Amapá } \\
\text { ( ) Bahia } \\
\text { ( ) Distrito Federal } \\
\text { ( ) Goiás } \\
\text { ( ) Mato Grosso } \\
\text { ( ) Minas Gerais } \\
\text { ( ) Paraíba } \\
\text { ( ) Pernambuco } \\
\text { ( ) Rio de Janeiro } \\
\text { ( ) Rio Grande do Sul } \\
\text { ( ) Roraima } \\
\text { ( ) São Paulo } \\
\text { ( ) Tocantins }\end{array}$ & $\begin{array}{l}\text { ( ) Alagoas } \\
\text { ( ) Amazonas } \\
\text { ( ) Ceará } \\
\text { ( ) Espírito Santo } \\
\text { ( ) Maranhão } \\
\text { ( ) Mato Grosso do Sul } \\
\text { ( ) Pará } \\
\text { ( ) Paraná } \\
\text { ( ) Piauí } \\
\text { ( ) Rio Grande do Norte } \\
\text { ( ) Rondônia } \\
\text { ( ) Santa Catarina } \\
\text { ( ) Sergipe }\end{array}$ \\
\hline
\end{tabular}

Fonte: Elaborado pelos autores

Notas:

${ }^{1}$ Questão de múltipla-escolha, pois o profissional auditor pode ter mais de uma especialização no mesmo grau de formação acadêmica. ${ }^{2}$ Cuidado metodológico realizado para saber quais os respondentes da amostra final, não compunham a listagem de Auditores Independentes do Cadastro Nacional de Auditores Independentes (CNAI), população alvo do objeto de pesquisa. 


\section{Bloco 2 - Ceticismo profissional dos auditores independentes}

Por favor, leia atentamente as assertivas abaixo. Marque 1 para discordo totalmente a 6 concordo totalmente. Não há respostas certas ou erradas.

\begin{tabular}{|c|c|c|c|c|c|c|c|c|}
\hline $\begin{array}{l}\text { Tipo de } \\
\text { Ceticismo }\end{array}$ & $\mathbf{Q}$ & Descrição da Questão & $\begin{array}{c}\text { Discordo } \\
\text { totalmente } \\
1\end{array}$ & 2 & 3 & 4 & 5 & $\begin{array}{c}\text { Concordo } \\
\text { totalmente } \\
6\end{array}$ \\
\hline \multirow{5}{*}{$\begin{array}{l}\text { Mente } \\
\text { questionadora } \\
\text { (MQ) }\end{array}$} & 01 & $\begin{array}{l}\text { Meus amigos consideram que } \\
\text { muitas vezes questiono o que eu } \\
\text { vejo e ouço. }\end{array}$ & & & & & & \\
\hline & 02 & $\begin{array}{l}\text { Frequentemente questiono o que } \\
\text { vejo e ouço. }\end{array}$ & & & & & & \\
\hline & 03 & $\begin{array}{l}\text { Muitas vezes rejeito as declarações } \\
\text { exceto quando tenho prova que } \\
\text { elas não são verdadeiras. }\end{array}$ & & & & & & \\
\hline & 04 & $\begin{array}{l}\text { Costumo notar inconsistências nas } \\
\text { explicações das outras pessoas. }\end{array}$ & & & & & & \\
\hline & 05 & $\begin{array}{l}\text { Gosto de determinar se o que leio } \\
\text { ou ouço é verdade. }\end{array}$ & & & & & & \\
\hline \multirow{5}{*}{$\begin{array}{l}\text { Suspensão do } \\
\text { julgamento (SJ) }\end{array}$} & 06 & Demoro a tomar decisões. & & & & & & \\
\hline & 07 & $\begin{array}{l}\text { Não gosto de decidir antes de } \\
\text { analisar toda as informações } \\
\text { disponíveis. }\end{array}$ & & & & & & \\
\hline & 08 & $\begin{array}{l}\text { Não gosto de tomar decisões } \\
\text { repentinamente. }\end{array}$ & & & & & & \\
\hline & 09 & $\begin{array}{l}\text { Gosto de me assegurar que } \\
\text { considerei todas as informações } \\
\text { disponíveis antes de tomar uma } \\
\text { decisão. }\end{array}$ & & & & & & \\
\hline & 10 & $\begin{array}{l}\text { Apenas decido quando obtenho } \\
\text { todas as informações necessárias } \\
\text { sobre um determinado assunto. }\end{array}$ & & & & & & \\
\hline \multirow{5}{*}{$\begin{array}{l}\text { Busca pelo } \\
\text { conhecimento } \\
\text { (BC) }\end{array}$} & 11 & $\begin{array}{l}\text { Penso que a aprendizagem é } \\
\text { emocionante. }\end{array}$ & & & & & & \\
\hline & 12 & Gosto de aprender. & & & & & & \\
\hline & 13 & $\begin{array}{l}\text { Gosto de descobrir novas } \\
\text { informações. }\end{array}$ & & & & & & \\
\hline & 14 & $\begin{array}{l}\text { Gosto da procura de } \\
\text { conhecimento. }\end{array}$ & & & & & & \\
\hline & 15 & $\begin{array}{l}\text { A perspectiva de conhecimento } \\
\text { entusiasma-me. }\end{array}$ & & & & & & \\
\hline \multirow{5}{*}{$\begin{array}{l}\text { Compreensão } \\
\text { interpessoal (CI) }\end{array}$} & 16 & $\begin{array}{l}\text { Gosto de compreender a razão } \\
\text { para o comportamento das ou-tras } \\
\text { pessoas. }\end{array}$ & & & & & & \\
\hline & 17 & $\begin{array}{l}\text { Estou interessado em saber o } \\
\text { que faz com que outras pessoas } \\
\text { se comportem de determinada } \\
\text { maneira. }\end{array}$ & & & & & & \\
\hline & 18 & $\begin{array}{l}\text { Interesso-me em saber as ações } \\
\text { que as pessoas tomam e as razões } \\
\text { para essas ações. }\end{array}$ & & & & & & \\
\hline & $19 \mathrm{R}$ & $\begin{array}{l}\text { Raramente me interesso o porque } \\
\text { das pessoas se comportarem de } \\
\text { determinada forma. }\end{array}$ & & & & & & \\
\hline & $20 \mathrm{R}$ & $\begin{array}{l}\text { O comportamento das outras } \\
\text { pessoas não me interessa. }\end{array}$ & & & & & & \\
\hline
\end{tabular}




\begin{tabular}{|c|c|c|c|c|c|c|c|c|}
\hline $\begin{array}{l}\text { Tipo de } \\
\text { Ceticismo }\end{array}$ & $\mathbf{Q}$ & Descrição da Questão & $\begin{array}{c}\text { Discordo } \\
\text { totalmente } \\
1\end{array}$ & 2 & 3 & 4 & 5 & $\begin{array}{c}\text { Concordo } \\
\text { totalmente } \\
6\end{array}$ \\
\hline \multirow{5}{*}{$\begin{array}{l}\text { Autoestima } \\
\text { (AE) }\end{array}$} & 21 & Tenho confiança em mim mesmo. & & & & & & \\
\hline & $22 \mathrm{R}$ & $\begin{array}{l}\text { Não me sinto seguro de mim } \\
\text { mesmo. }\end{array}$ & & & & & & \\
\hline & 23 & Estou seguro de mim. & & & & & & \\
\hline & 24 & $\begin{array}{l}\text { Estou confiante nas minhas } \\
\text { capacidades. }\end{array}$ & & & & & & \\
\hline & 25 & Sinto-me bem comigo mesmo. & & & & & & \\
\hline \multirow{5}{*}{$\begin{array}{l}\text { Autonomia } \\
\quad(\mathrm{AN})\end{array}$} & 26R & $\begin{array}{l}\text { Tendo a aceitar imediatamente o } \\
\text { que as outras pessoas me dizem. }\end{array}$ & & & & & & \\
\hline & $27 \mathrm{R}$ & $\begin{array}{l}\text { Costumo aceitar as coisas que } \\
\text { vejo, ouço ou leio. }\end{array}$ & & & & & & \\
\hline & $28 \mathrm{R}$ & $\begin{array}{l}\text { Costumo aceitar as explicações } \\
\text { das outras pessoas sem mais } \\
\text { reflexão. }\end{array}$ & & & & & & \\
\hline & $29 \mathrm{R}$ & $\begin{array}{l}\text { É fácil as outras pessoas } \\
\text { convencerem-me. }\end{array}$ & & & & & & \\
\hline & $30 \mathrm{R}$ & $\begin{array}{l}\text { Na maioria das vezes concordo } \\
\text { com o que as pessoas do meu } \\
\text { grupo de trabalho pensam. }\end{array}$ & & & & & & \\
\hline
\end{tabular}

Fonte: Adaptado de Hurtt (2010).

Legenda: "R" indica item com pontuação reversa.

\section{Bloco 3 - Traços de personalidade}

Por favor, leia atentamente as assertivas abaixo. Marque 1 para discordo totalmente a 5 concordo totalmente. Não há respostas certas ou erradas.

\begin{tabular}{|c|c|c|c|c|c|c|c|c|}
\hline $\begin{array}{l}\text { Características } \\
\text { comportamentais }\end{array}$ & $\mathbf{Q}$ & Descrição da Questão & $\begin{array}{c}\text { Discordo } \\
\text { totalmente } \\
1 \\
\end{array}$ & 2 & 3 & 4 & 5 & $\begin{array}{c}\text { Concordo } \\
\text { totalmente } \\
6 \\
\end{array}$ \\
\hline \multirow{2}{*}{ Extroversão (E) } & 31 & $\begin{array}{l}\text { Eu me vejo como alguém } \\
\text { extrovertido, entusiasta }\end{array}$ & & & & & & \\
\hline & $32 \mathrm{R}$ & $\begin{array}{l}\text { Eu me vejo como alguém } \\
\text { reservado, quieto }\end{array}$ & & & & & & \\
\hline \multirow{2}{*}{ Consciência (C) } & 33 & $\begin{array}{l}\text { Eu me vejo como alguém } \\
\text { autodisciplinado }\end{array}$ & & & & & & \\
\hline & $34 \mathrm{R}$ & $\begin{array}{l}\text { Eu me vejo como alguém } \\
\text { desorganizado, descuidado }\end{array}$ & & & & & & \\
\hline \multirow{2}{*}{$\begin{array}{l}\text { Abertura } \\
\text { (A) }\end{array}$} & 35 & $\begin{array}{l}\text { Eu me vejo como alguém aberto } \\
\text { a novas experiências }\end{array}$ & & & & & & \\
\hline & $36 \mathrm{R}$ & $\begin{array}{l}\text { Eu me vejo como alguém } \\
\text { convencional, sem criatividade }\end{array}$ & & & & & & \\
\hline \multirow[t]{2}{*}{ Sociabilidade (S) } & 37 & $\begin{array}{l}\text { Eu me vejo como alguém } \\
\text { simpático }\end{array}$ & & & & & & \\
\hline & $38 \mathrm{R}$ & Eu me vejo como alguém crítico & & & & & & \\
\hline \multirow{2}{*}{ Neuroticismo (N) } & 39 & $\begin{array}{l}\text { Eu me vejo como alguém calmo, } \\
\text { emocionalmente estável }\end{array}$ & & & & & & \\
\hline & $40 \mathrm{R}$ & $\begin{array}{l}\text { Eu me vejo como alguém } \\
\text { ansioso, chateio-me facilmente }\end{array}$ & & & & & & \\
\hline
\end{tabular}

Fonte: Adaptado de Gosling, Rentfrow e Swann (2003).

Legenda: "R" indica item com pontuação reversa. 